\title{
Fabrication of Ni stamp with high aspect ratio, two-leveled, cylindrical microstructures using dry etching and electroplating
}

\author{
Petersen, Ritika Singh; Keller, Stephan Sylvest; Hansen, Ole; Boisen, Anja
}

Published in:

Journal of Micromechanics and Microengineering

Link to article, DOI:

$10.1088 / 0960-1317 / 25 / 5 / 055021$

Publication date:

2015

Document Version

Peer reviewed version

Link back to DTU Orbit

Citation (APA):

Petersen, R. S., Keller, S. S., Hansen, O., \& Boisen, A. (2015). Fabrication of Ni stamp with high aspect ratio, two-leveled, cylindrical microstructures using dry etching and electroplating. Journal of Micromechanics and Microengineering, 25(5), [055021]. https://doi.org/10.1088/0960-1317/25/5/055021

\section{General rights}

Copyright and moral rights for the publications made accessible in the public portal are retained by the authors and/or other copyright owners and it is a condition of accessing publications that users recognise and abide by the legal requirements associated with these rights.

- Users may download and print one copy of any publication from the public portal for the purpose of private study or research.

- You may not further distribute the material or use it for any profit-making activity or commercial gain

- You may freely distribute the URL identifying the publication in the public portal 


\title{
FABRICATION OF NI STAMP WITH HIGH ASPECT RATIO, TWO-LEVELED, CYLINDRICAL MICROSTRUCTURES USING DRY ETCHING AND ELECTROPLATING
}

\author{
Ritika Singh Petersen, Stephan Sylvest Keller, Ole Hansen ${ }^{1}$, and Anja Boisen \\ DTU Nanotech, Department of Micro- and Nanotechnology, Technical University of Denmark, Building 345E, DK-2800 Kongens Lyngby, \\ Denmark \\ ${ }^{1}$ CINF - Center for Individual Nanoparticle Functionality, Technical University of Denmark, Building 345E, DK-2800 Kongens Lyngby, \\ Denmark \\ e-mail: risi@nanotech.dtu.dk
}

\begin{abstract}
We describe a process for the fabrication of a Ni stamp that is applied for microstructuring of polymers by hot embossing. The target devices are microcontainers for the potential application in oral drug delivery. Each container is a three dimensional, cylindrical, high aspect ratio microstructure obtained by definition of a reservoir and a separating trench with different depths of $85 \mu \mathrm{m}$ and $125 \mu \mathrm{m}$, respectively, in a single embossing step. The fabrication of the required two leveled stamp is done by a modified DEEMO (Dry etching, electroplating and molding) process. Dry etching using the Bosch process and electroplating are optimized to obtain a stamp with smooth stamp surfaces and a positive sidewall profile. Using this stamp, hot embossing is performed successfully with excellent yield and high replication fidelity.
\end{abstract}

Keywords: Nickel stamp, Bosch process, electroplating, hot embossing, microcontainers

\section{INTRODUCTION}

Simultaneous with the development of new NEMS and MEMS techniques, the use of nano- and microstructures and devices for biomedical and pharmaceutical applications has proliferated. The devices were fabricated in standard silicon based materials or photosensitive polymers but recently the focus has changed to biocompatible polymers [1]. For low cost and high throughput processing of polymers, hot embossing has emerged as a viable fabrication method [2]. In order to define devices in polymers using the hot embossing technique, a microfabricated stamp is required. To achieve a reliable, high fidelity embossing, a high quality stamp must be used and the embossing parameters have to be optimized with respect to critical parameters in the application.

The target device in this work is a microcontainer based drug delivery device that has potential to increase bioavailability of drugs when taken orally [3]. Such a microcontainer is a two-leveled structure consisting of a cylindrical container bottom and a ring-shaped container wall defining the size of the inner reservoir [4]. Recently, we have for the first time demonstrated embossing of microcontainers in the biodegradable and biocompatible polymer, Poly-L-Lactic Acid (PLLA) using SU-8 stamps, but alas SU-8 stamps are not robust enough to last more than a few embossing runs [5]. For other applications, new methods for preparation of stamps in more stable materials like steel, copper or nickel have been developed [6-8]. Among the most frequently used stamp materials, Ni is very robust and can be easily electroplated on a master template to create complex three dimensional structures at high resolution [9]. Another advantage of a Ni stamp is that it can be used for mass production in roll-to-roll processing [10]. 
Ni stamps can be fabricated with two well-known processes: LIGA (Lithography, Electroplating, and Molding) [9] or DEEMO (Dry etching, electroplating and molding) [11]. In both processes, a master is first fabricated either in photoresist by lithography or in Si by lithography and dry etching. Subsequently, Ni is electroplated and the master is removed. This electroplated $\mathrm{Ni}$ structure is used for embossing in polymers. The availability of photoresists like SU-8 that allow definition of high aspect ratio structures with very smooth surfaces without use of expensive X-ray synchrotron lithography makes LIGA a viable option for the preparation of Ni stamps [9]. However, it is very difficult to completely remove the SU-8 master from the electroplated Ni stamp in particular in narrow trenches and the resulting increased surface roughness might affect the hot embossing process [12]. Guo et al. have been able to emboss single level structures with a minimal width of $40 \mu \mathrm{m}$ and aspect ratio 8 using a Ni stamp prepared with the LIGA process [13].

In this work a microcontainer fabrication process based on DEEMO has been developed. The concept is illustrated in Fig.1, which also defines the specific terms used throughout the paper. More specifically, we describe in details the process that was developed for fabrication of Ni stamps with two-leveled cylindrical microstructures using DEEMO. Tanzi et al. have fabricated two leveled microdevices with rectangular features using the DEEMO process [14]. Park et al. presented the fabrication of a two-leveled Ni stamp with cylindrical features [15]. In both cases, the aspect ratio of the microstructures is only around 2. Here we show, to our best knowledge, for the first time the fabrication of a Ni stamp with two-leveled cylindrical microstructures with vertical dimensions $>80 \mu \mathrm{m}$ and aspect ratio $>8$ using an optimized DEEMO process.

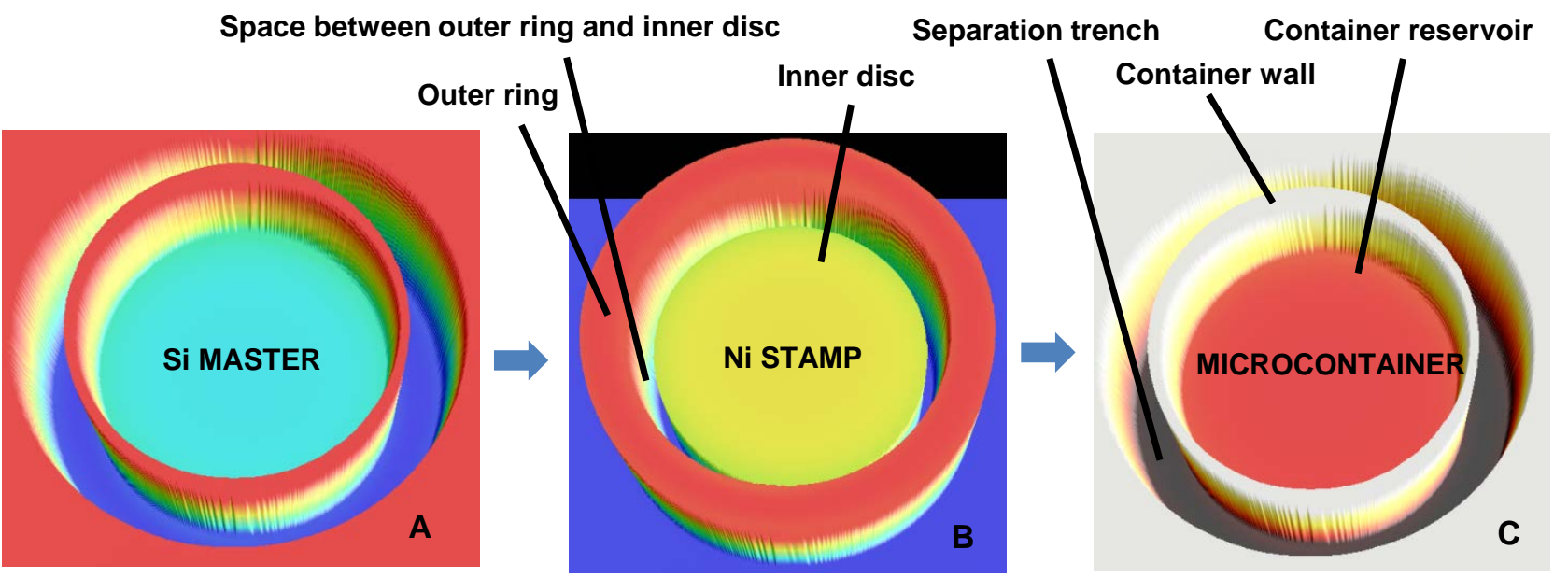

Fig. 1.Various features of the stamp and microcontainers and subsequent translation of the Si master (A) into a Ni stamp (B) and then further into biopolymer microcontainers $(C)$ with the inner reservoir, walls around it and the separation trench between the container and the surrounding polymer film.

In order to obtain a good polymer replication of the stamp, the demolding forces have to be minimized to avoid the damage of the replica during stamp removal. This poses a number of requirements for the fabrication of the Ni stamp (Fig.2.A): a) the stamp must have very smooth sidewalls to minimize the frictional forces between the polymer structures and the Ni stamp; b) the sidewalls of the stamp should preferably have a positive taper in order to minimize the interlocking forces; c) there should not be any undercut at the top of the features to avoid mechanical interlocking [16].

Due to the high aspect ratio trenches and the depth dimensions of the microstructures (Fig.2.B), photolithography, deep reactive ion etching (DRIE) and Si etching after electroplating has to be optimized. Additional challenges that the design requirements pose during the fabrication process are: 1) the two-leveled geometry poses misalignment and masking issues, 2) the deep circular geometry of the inner reservoir causes problems during the etching of the Si master to 
release the Ni stamp, and 3) the thin vertical walls of the Si master require minimization of the lateral etch to prevent loss of structural integrity. In order to meet the design requirements of the Ni stamp, the deep reactive ion etching (DRIE) process for Si was optimized and microstructures with high aspect ratio of 8 could be obtained. Finally, Ni was electroplated to obtain stamps with the required features, smooth surfaces and sidewalls with a positive slope. The $\mathrm{Ni}$ stamp was used to emboss microcontainers in PLLA films, and high fidelity replication of the stamp was demonstrated with a process yield of $100 \%$.
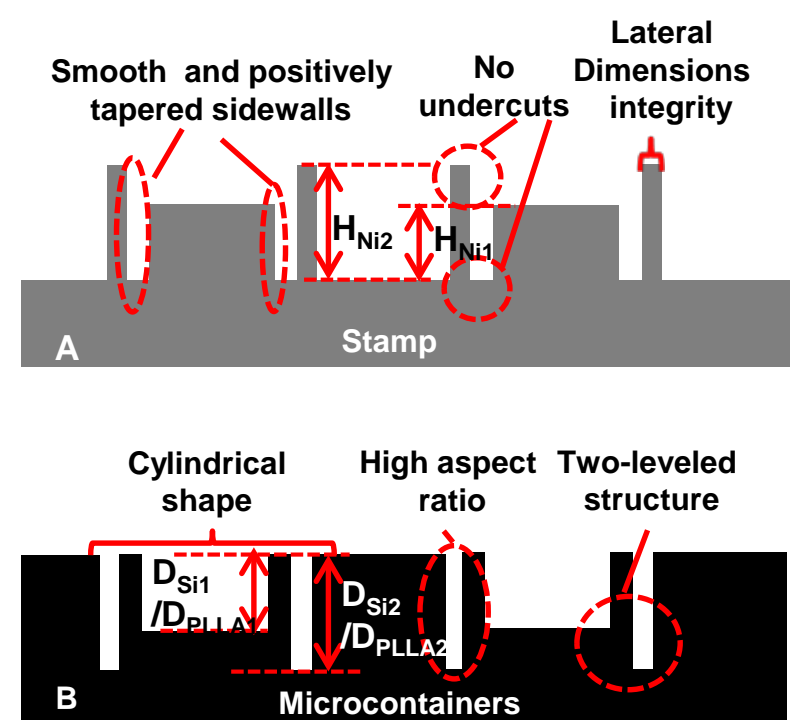

Fig. 2. Design considerations and critical dimensions for fabrication of the Ni stamp (A) and corresponding microcontainer patterns in $\mathrm{Si}$ master or PLLA film (B). The two critical dimensions are: the reservoir depth in Si master ( $\left.D_{S i 1}\right)$ and PLLA (D $D_{\text {PLA1 }}$ ) or the corresponding inner circle height on the stamp $\left(\mathrm{H}_{\mathrm{Ni} 1}\right)$, and the separation trench depth in Si master $\left(\mathrm{D}_{\mathrm{Si} 2}\right)$ and PLLA $\left(\mathrm{D}_{\mathrm{PLLA} 2}\right)$ or the corresponding height of the outer ring on the stamp $\left(\mathrm{H}_{\mathrm{Ni} 2}\right)$

\section{METHODS}

\subsection{Stamp design}

The stamp contains 16 square arrays with $20 \times 20$ individual stamp units. Each stamp unit corresponds to one microcontainer and thus the stamp design enables fabrication of 6400 devices in a single embossing run. Fig.1.B shows an individual stamp unit. It consists of two parts, an inner disc and an outer ring structure and there are three important parameters (Fig.1.A-C): 1) The diameter of the inner disk, which translates into the microcontainer reservoir, 2) the space between the inner disc and the outer ring that corresponds to the wall of the container and 3) the width of the outer ring structure, which transforms into the separation trench between the microcontainer and the surrounding polymer film. The inner diameter of the outer ring structure corresponding to the final diameter of the microcontainers is kept constant at $300 \mu \mathrm{m}$. To achieve containers with different wall thicknesses of 10, 20,30, and $40 \mu \mathrm{m}$ the diameter of the inner disc is varied from 220, over 240, 260, to $280 \mu \mathrm{m}$. Furthermore, the width of the outer ring structure is varied from 20 , over 30 , 40, to $50 \mu \mathrm{m}$. The design variations are chosen to evaluate how thin the sidewalls can be made before losing their mechanical stability. These values of the container dimensions have been chosen based on the previous work done [4, 17] and the constraints imposed by the aspect ratio that can be produced in polymer using a hot embossing process. The PLLA microcontainer with the wall thickness of $10 \mu \mathrm{m}$ and reservoir depth of $80 \mu \mathrm{m}$ possesses similar volume for drug as the SU-8 microcontainer discussed in Marizza et al. and Nielsen et al. 


\subsection{Stamp fabrication and hot embossing}

The complete process flow is illustrated in Fig.3, which includes fabrication of Si master, stamp, and polymer replica. First a $1 \mu \mathrm{m}$ thick $\mathrm{SiO}_{2}$ film is grown on a 4-inch (100) Si wafer using wet thermal oxidation at $1100^{\circ} \mathrm{C}$ for $2 \mathrm{hr} 40 \mathrm{~min}$ (Fig.3.A) This $\mathrm{SiO}_{2}$ thickness is required for the oxide layer to act as mask in the later Si dry etch process. Positive photoresist AZ5214E (1.5 $\mu \mathrm{m}$ thick) is spin coated on a HMDS treated wafer at $4000 \mathrm{rpm}$ and pre-baked at $90^{\circ} \mathrm{C}$ for 90 sec on a hotplate. AZ5214E is patterned on the oxide layer using a first photolithographic mask. This first mask (base mask) is a dark field glass mask with chrome everywhere except the inner disc and the outer ring. This mask fully defines the lateral geometry of the microstructure. The resist is exposed with a UV dose of $49 \mathrm{~mJ} / \mathrm{cm}^{2}$ and then developed for 60 $\mathrm{sec}$ in AZ351B developer (Fig.3.B). A short oxygen plasma descum process $\left(\mathrm{O}_{2}=200 \mathrm{sccm}, \mathrm{N}_{2}=70 \mathrm{sccm}\right.$, at $300 \mathrm{~W}$ for 3 $\mathrm{min}$ ) is run to remove residues of photoresist from the developed areas. The pattern is then transferred into the oxide using a dry etch recipe (Fig.3.C) in a STS Advanced Oxide Etcher (AOE). The parameters used in the recipe are as follows: Coil power $=1300 \mathrm{~W}$, platen power $=200 \mathrm{~W}$, platen temperature $=0^{\circ} \mathrm{C}$, He flow rate $=174 \mathrm{sccm}, \mathrm{C}_{4} \mathrm{~F}_{8}$ flow rate $=5$ $\mathrm{sccm}, \mathrm{H}_{2}$ flow rate=4 sccm, and pressure=4 mTorr. After the dry oxide etch, a $1 \mathrm{~min}$ dip of the wafers in buffered $\mathrm{HF}$ (bHF) is used to remove residues of oxide left in the etched areas. Subsequently, the first layer of photoresist is stripped using plasma ashing with the following parameters: $\mathrm{O}_{2}=400 \mathrm{sccm}, \mathrm{N}_{2}=70 \mathrm{sccm}$, at $1000 \mathrm{~W}$ for $15 \mathrm{~min}$ (Fig.3.D). A second photoresist layer is spin coated on the patterned oxide layer (Fig.3.E). This time, the $1.5 \mu \mathrm{m}$ thick resist is exposed with the dose of $84 \mathrm{~mJ} / \mathrm{cm}^{2}$ using a second photolithographic mask (separation mask) and developed for 90 sec (Fig.3.F). This second mask is also a dark field mask with chrome everywhere except the outer ring. After the second photolithography, descum is done at higher oxygen flow rate of $300 \mathrm{sccm}$ and power of $450 \mathrm{~W}$, while keeping the $\mathrm{N}_{2}$ flow rate and the time as before.

With the combined patterns of the two masks ( $\mathrm{SiO}_{2}$ and photoresist, respectively), a DRIE of $\mathrm{Si}$ is performed to a target depth of about $65 \mu \mathrm{m}$ (Fig.3.G) in STS Pegasus. Then, the photoresist is stripped and the reservoir pattern in the $\mathrm{SiO}_{2}$ is exposed (Fig.3.H). The second DRIE of Si is then performed to a target depth of another $60 \mu \mathrm{m}$ (Fig.3.I). The etch parameters for both DRIE steps are described in detail in the next section on DRIE optimization. It should be noted here that it is the oxide layer that acts as the pattern defining mask for the DRIE steps. The resist only protects the inner reservoir of the Si master during the first dry etch. To avoid misalignment and minimize the risk of micromasking effects due to redeposition of photoresist debris during the first etch step, the outer rings in the second mask were $10 \mu \mathrm{m}$ wider than on the first one (Fig.3.F), The result of the two DRIE processes is a two level structure in Si (Fig.3.J). After removal of the $\mathrm{SiO}_{2}$ mask in bHF, another layer of $500 \mathrm{~nm}$ thick thermal $\mathrm{SiO}_{2}$ is grown on this two-leveled Si structure and etched in bHF. This step is performed to reduce the sidewall roughness in the form of vertical striations and horizontal scallops due to the Bosch process [18]. 
A
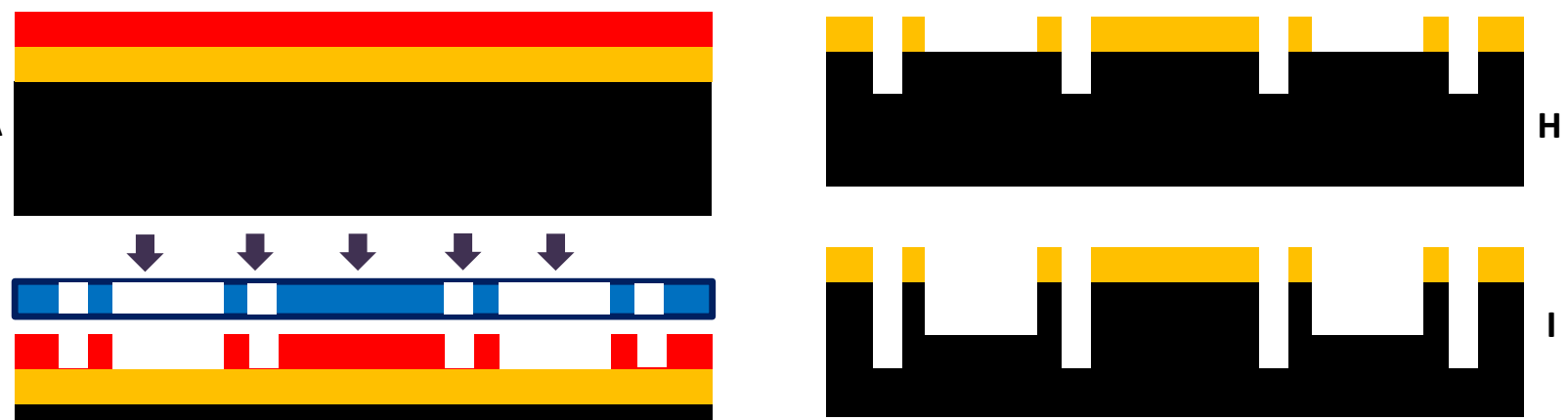

B
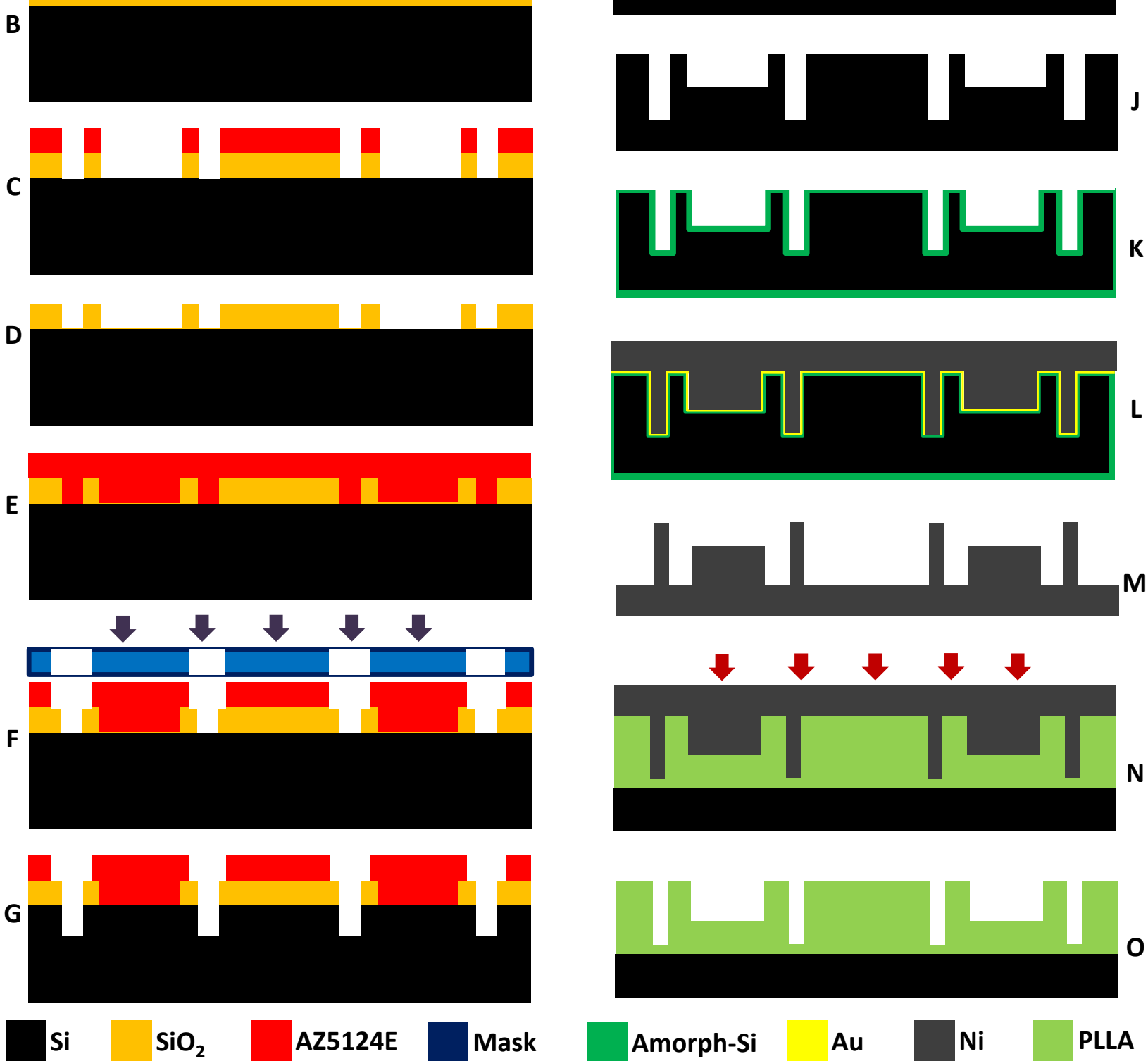

Amorph-Si

$\mathrm{Au}$

PLLA

Fig.3. Process flow for the fabrication of Si master, Ni stamp and polymer replica: A. Spin coating of photoresist on a thermally oxidized Si wafer, B. Exposure of AZ5214E photoresist using base mask and development, C. Pattern transfer to silicon dioxide using AOE, D. AZ5214E resist stripping, E. Spin coating of second AZ5214E photoresist layer, F. Exposure of AZ5214E using separation mask and development, G. First DRIE etch, H. AZ5214E stripping, I. Second DRIE etch, J. Oxide mask removal, sacrificial oxide growth and sacrificial oxide removal to make sidewalls smoother, K. Amorphous Si deposition on Si master, L. Au deposition on Si master and $\mathrm{Ni}$ electroplating, $\mathrm{M}$. Wet $\mathrm{KOH} \mathrm{Si}$ etch to release the Ni stamp and coating with fluorocarbon, N. Embossing in spin coated PLLA film with the Ni stamp, O. Demolding to finish replication of microcontainers in PLLA. 
Next, the Si master is prepared for electroplating of Ni. First, a thin release layer of around $200 \mathrm{~nm}$ amorphous Si is deposited on the master using low pressure chemical vapor deposition (LPCVD) in $\mathrm{SiH}_{4}$ at $560^{\circ} \mathrm{C}$ for $1 \mathrm{hr} 20 \mathrm{~min}$ (Fig.3.K). Then $100 \mathrm{~nm}$ of $\mathrm{Cr} / \mathrm{Au}$ are sputtered to get a conformal metal coating serving as a seed layer for electroplating. Next, $500 \mu \mathrm{m}$ thick $\mathrm{Ni}$ is electroplated in a plating bath of aqueous nickel sulphamate, boric acid and sulfamic acid kept at $51^{\circ} \mathrm{C}$ and $\mathrm{pH} 3.5-3.8$ (Fig.3.L). The current is linearly increased to $0.5 \mathrm{~A}$ during 15 min followed by ramping to $1.5 \mathrm{~A}$ during additional $15 \mathrm{~min}$. The current is maintained at $1.5 \mathrm{~A}$ for $30 \mathrm{~min}$ and increased to the final value of $6.5 \mathrm{~A}$ during 15 $\min$. Then the electroplating is continued for approximately $3 \mathrm{hr}$ until a final set-point charge of 26.8 Ah is reached. The complete process takes around $12 \mathrm{hr}$ to obtain $500 \mu \mathrm{m}$ thick Ni conformably electroplated on the Si master. The Si master is then etched in $28 \mathrm{wt} \% \mathrm{KOH}$ at $80^{\circ} \mathrm{C}$ for $7-8 \mathrm{hr}$ and a released Ni stamp is obtained (Fig.3.M). A molecular layer of Perfluorodecyltrichlorosilane (FDTS) is deposited on the Ni stamp using molecular vapor deposition (MVD) [19]. This improves the separation of the stamp and the molded polymer replica by reducing the adhesion forces between the two parts [15].

Finally, hot embossing in PLLA is performed. A 15\%wt solution of PLLA in dichloromethane (DCM) is prepared and spin coated on a Si wafer at $500 \mathrm{rpm}$ at an acceleration of $500 \mathrm{rpm} / \mathrm{min}$ for $1 \mathrm{~min}$. This results in a polymer film with a thickness of around $80 \mu \mathrm{m}$. Two layers of PLLA solution are spin coated to achieve a thickness of around 150-160 $\mu \mathrm{m}$. The spin coated wafer is then left for $15 \mathrm{~min}$ to allow the solvent to evaporate. The Ni stamp is used to emboss the PLLA film at $90^{\circ} \mathrm{C}$ for $15 \mathrm{~min} 1.9 \mathrm{MPa}$ (Fig.3.N) [20]. The pressure is maintained during the cooling stage. The stack of Ni stamp and PLLA film is cooled down to $50^{\circ} \mathrm{C}$, demolding is performed and the microcontainer patterns are replicated in the PLLA. (Fig.3.O). The entire setup is kept at atmospheric pressure.

\subsection{DRIE optimization}

To perform the optimization of lithography and etching processes, test wafers were used. These wafers were Si wafers with a $1 \mu \mathrm{m}$ thick oxide layer patterned with either the base or the separation mask. The parameters for photolithography were the same as the ones described for the first lithographic step above. The test structures were used to identify the dry etch parameters that result in smooth but tapered walls, while at the same time minimizing any undercut.

\begin{tabular}{|c|c|c|c|}
\hline \multicolumn{2}{|c|}{ Etch cycle time (sec) } & \multirow{2}{*}{$\begin{array}{l}\text { Change from } \\
\text { reference } \\
\text { etch cycle (\%) }\end{array}$} & \multirow{2}{*}{$\begin{array}{l}\text { Number } \\
\text { of cycles }\end{array}$} \\
\hline $\begin{array}{l}\text { First } \\
\text { cycle }\end{array}$ & Final cycle & & \\
\hline 2.4 & 2.64 & 10 & 230 \\
\hline 2.4 & 2.52 & 5 & 270 \\
\hline 2.4 & 2.46 & 2.5 & 290 \\
\hline 2.4 & 2.4 & 0 & 300 \\
\hline 2.4 & 2.34 & -2.5 & 310 \\
\hline 2.4 & 2.28 & -5 & 330 \\
\hline 2.4 & 2.16 & -10 & 370 \\
\hline 2.46 & 2.34 & 2.5 to -2.5 & 300 \\
\hline 2.52 & 2.28 & 5 to -5 & 300 \\
\hline 2.64 & 2.16 & 10 to -10 & 300 \\
\hline
\end{tabular}


Table.1. Optimization of DRIE process by ramping the etch cycle time and adjusting the number of etch cycles. All the other parameters are kept constant. The duration of the reference cycle in Process D is $2.4 \mathrm{sec}$.

The standard process (called Process D), that is recommended by the manufacturer of STS Pegasus, was chosen as the starting point for optimization. The etch cycle of Process $D$ has the following parameters: $\mathrm{SF}_{6}=275 \mathrm{sccm}, \mathrm{O}_{2}=5 \mathrm{sccm}$, cycle time $=2.4 \mathrm{sec}$, pressure $=26 \mathrm{mTorr}$, coil power $=2500 \mathrm{~W}$, platen power $=35 \mathrm{~W}$, temperature $=0^{\circ} \mathrm{C}$. The passivation cycle has the following parameters: $\mathrm{C}_{4} \mathrm{~F}_{8}=150 \mathrm{sccm}$, cycle time $=2.0 \mathrm{sec}$, pressure $=20 \mathrm{mTorr}$, coil power $=2000 \mathrm{~W}$, platen power $=0 \mathrm{~W}$, temperature $=0^{\circ} \mathrm{C}$. Initial runs on test wafers using Process $\mathrm{D}$ were performed and resulted in micrograss formation. Therefore Process D was modified by increasing the oxygen flow rate from $5 \mathrm{sccm}$ to $15 \mathrm{sccm}$.

To optimize the sidewall tapering, the etch cycle time was ramped up and/or down from 2.4 sec as detailed in Table.1. While keeping all the other parameters constant except the number of cycles, the experiments were done in with $-10,-5$, $-2.5,0,2.5,5,10 \%$ change from the standard etch time of $2.4 \mathrm{sec}$. After initial measurements made on the Si test wafers for the calculation of the etch rate, the number of cycles was adjusted to achieve a depth of between 110-130 $\mu \mathrm{m}$ for the separation trench. Micrograss formation had to be avoided at any cost since the surface roughness is more important for the demolding forces than the wall profile [21]. After the optimization on test wafers, the results were used for the fabrication of actual two-leveled microstructures.

\section{RESULTS AND DISCUSSION}

\subsection{Etch mask patterning and removal}

Initially an isotropic wet etch for $10 \mathrm{~min}$ in bHF solution was performed to pattern the $\mathrm{SiO}_{2}$ etch mask. During the dry etching of Si an unwanted ring was formed very close to the desired structures as shown in Fig.4.A. The isotropic nature of the wet etch results in a non-vertical edge of the oxide mask. It was concluded that the ring occurs due to micromasking caused by debris from the oxide layer. Hence, a dry etch was chosen for patterning the oxide layer in order to avoid these micromasking issues. This gave improved results for the test structures as can be seen in Fig.4.B. For photoresist stripping too, a dry etch process was preferred compared to wet stripping in acetone in order to remove all photoresist residues. 

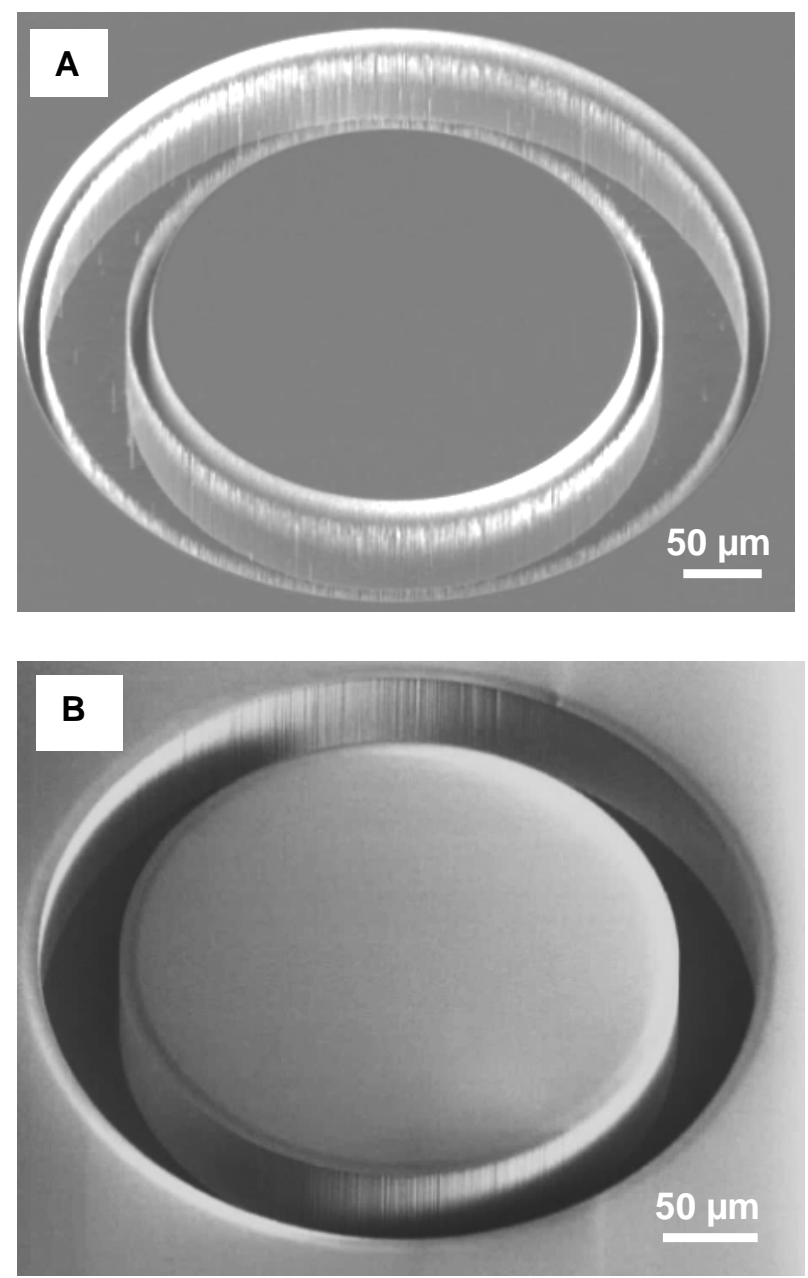

Fig. 4. A. Unwanted ring formation during the first DRIE step after isotropic wet etch of the oxide mask in BHF, B. No unwanted ring formation during the first DRIE when dry etch is done for patterning of the oxide mask.

\subsection{DRIE optimization}

With the oxygen flow fixed at 15 sccm, the DRIE process optimization was done by ramping the etch cycle as described in Table.1. The basic concept behind ramping the etch cycle time is to vary the relative etch and passivation rates [22, 23]. Alternatively, this ratio could also be changed by ramping etch and passivation gas flows [22-24]. Fig.5 shows the result of some of the optimization performed in this work. When the etch time was ramped down from 2.4 sec to 2.16 ($10 \%$ ), increased roughness close to the walls and formation of tall micrograss can be observed (Fig.5.A). When the etch cycle was kept constant at $2.4 \mathrm{sec}(0 \%)$, roughness at the bottom of the walls could be seen (Fig.5.B). On the other hand, when the etch cycle was ramped up from 2.4 to $2.56(+5 \%)$, micrograss formation could be completely avoided (Fig.5.C). For the change of $-10 \%$ and $0 \%$ in the etch cycle, the roughness increased because of the incomplete removal of the passivation layer during the etch cycle. The absence of micrograss for $5 \%$ can be attributed to the complete removal of the passivation layer deposited in the previous passivation cycle during the etch cycle. However, ramping up $(+5 \%)$ resulted in completely vertical sidewalls, a slight undercut at the top of the structure and larger scallop sizes. On the other hand, ramping down (-10\%) resulted in positive tapering of sidewalls at the cost of increased surface roughness and micrograss formation (Fig.5.D-F). 


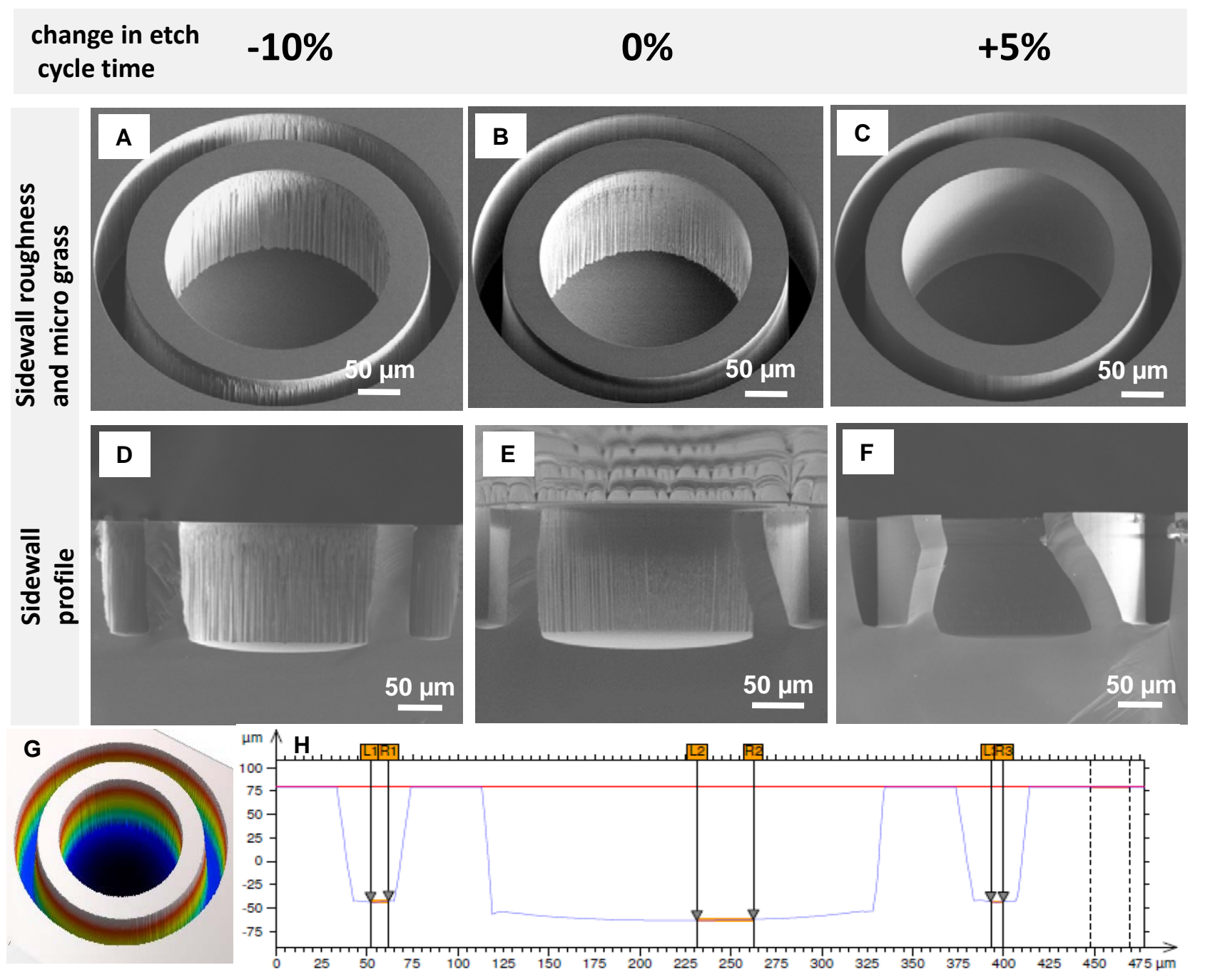

Fig.5. SEM images of $40 \mu \mathrm{m}$ wall microcontainers with a separation trench width of $30 \mu \mathrm{m}$ illustrating the effect of etch cycle ramping on the surface roughness $(A-C)$ and sidewall tapering (D-F). A,D represent $-10 \%, B, E$ represent $0 \%$ and C,F represent $+5 \%$, changes in etch time from standard $2.4 \mathrm{sec}$. 3D optical profilometer analysis $(G)$. The DRIE process was optimized to get smooth and positively tapered wall profiles as shown in the optical profilometer line-scan $(\mathrm{H})$.

Using these results, it was decided to ramp down the etch cycle from 2.52 to $2.28 \mathrm{sec}$ for 300 cycles. When ramping from 2.52 to $2.28 \mathrm{sec}$, the process started with a longer etch cycle time compared to the standard process D, thereby allowing smooth wall formation (Fig. 5.G) while the ramping down of the etch time allowed formation of a positive profile Fig.5.H). From the optical profiler measurements, it can be concluded that aspect ratio dependent etching (ARDE) occurred. The centre reservoir of the Si master which has a diameter ranging from 220-280 $\mu$ m etched faster than the thin separation trench with a width of 20-50 $\mu \mathrm{m}$. This difference in etch depth was around $20 \mu \mathrm{m}$. Taking ARDE into account, after some corrections for etch rate, 150 cycles for each dry etch step were chosen such that separation trench depth of around $120 \mu \mathrm{m}$ and a reservoir depth of around $80 \mu \mathrm{m}$ could be achieved.

Finally, the dependency of the etch process on the mask material was evaluated. While keeping all the parameters constant, only the masking layer was changed. Two types of test wafers were fabricated, either with the patterned oxide layer or with the resist layer as the main masking layer. No apparent difference between the wafers was observed in 
SEM and it was concluded that the masking material should not have a significant impact on the microstructures for the selected process parameters.

\subsection{Si master fabrication}

The experiments were transferred from the test structures to the actual process with two etching steps to achieve the two-leveled structure. In a first run, the parameters for both photolithographic steps were kept the same with an exposure dose of $49 \mathrm{~mJ} / \mathrm{cm}^{2}$ and a development step of $60 \mathrm{sec}$. However, after the first DRIE step, high roughness and micrograss were seen (Fig.6.A), which deteriorated the structures even further during the second etch step. This roughness arises from incomplete development of the photoresist during the second photolithography step. Compared to the test structures, the second photoresist layer is spin coated on a substrate with an oxide layer with $1 \mu \mathrm{m}$ deep trenches. Thus, when it is exposed and developed, residues are left at the edges of the trenches, which results in
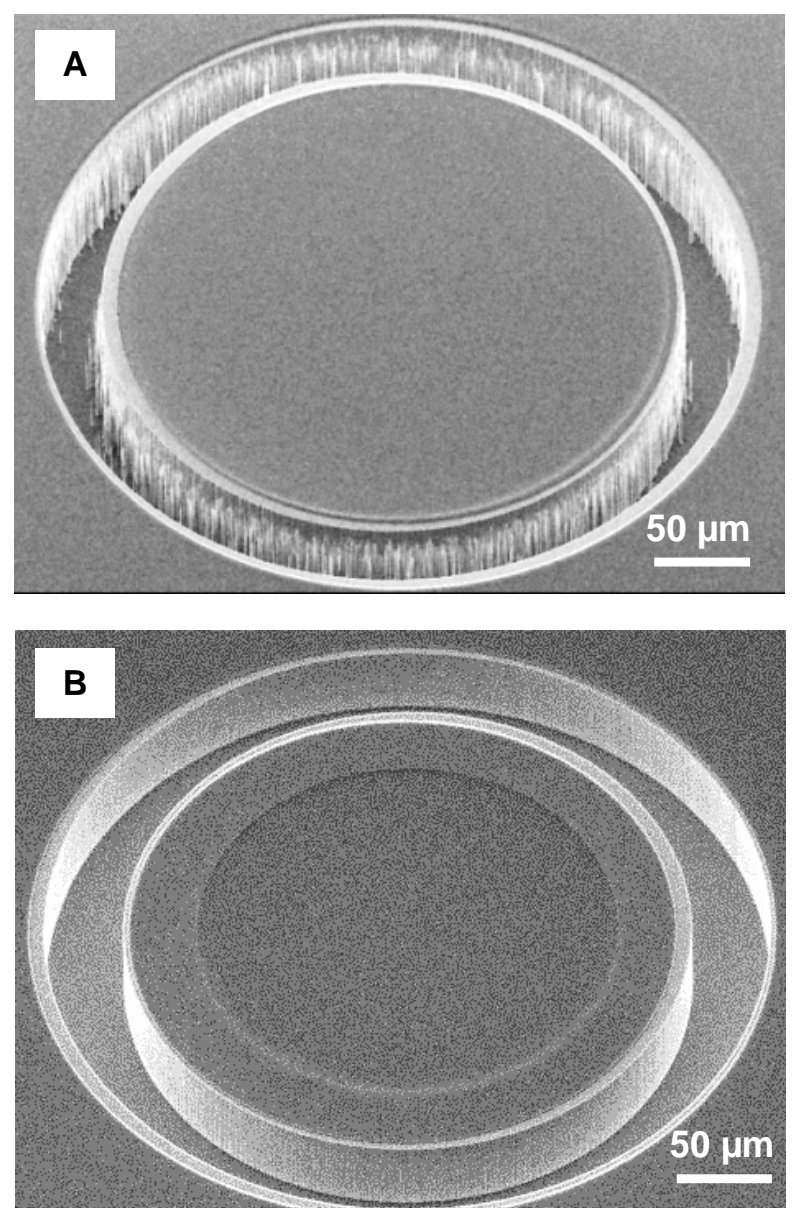

Fig.6. A. Micrograss close to the walls after the first step of DRIE, B. Improved structures after the first step of DRIE for the same etch parameters with modified second photolithography..

micromasking and increased roughness during the DRIE step. The second photolithography step was modified accordingly. The $1.5 \mu \mathrm{m}$ thick $A Z$ resist was exposed at a higher dose of $84 \mathrm{~mJ} / \mathrm{cm}^{2}$ and developed for longer time $(90$ $\mathrm{sec}$ ). The descum was made harsher by increasing the oxygen flow rate (300 sccm) and power (450 W) while keeping the rest of the parameters constant. Even though more resist was sacrificed in the descum process by this measure, the remaining thickness was still sufficient to protect the reservoir of the Si master during the first DRIE step of 150 cycles. 
With the modified photolithography steps, the microstructures improved considerably and results identical to the test wafers could be obtained (Fig.6.B).

The etch cycle time was ramped from 2.52 to $2.4 \mathrm{sec}$ for the first 150 cycles. The photoresist was stripped and then the second etch was ramped from 2.4 to $2.28 \mathrm{sec}$ for the next 150 cycles. By ramping the etch cycle like this a positive taper with an angle of around $87.8^{\circ}$ was obtained as shown in the cross section image (Fig.7.A). It is important that after stripping of the photoresist, the second DRIE process starts with a passivation cycle. In the oxygen plasma both the resist and the fluorocarbon passivation on the walls of the Si structure are removed. Without an initial passivation cycle, the first etch cycle of the second DRIE step starts etching the newly exposed walls, which results in high surface roughness.
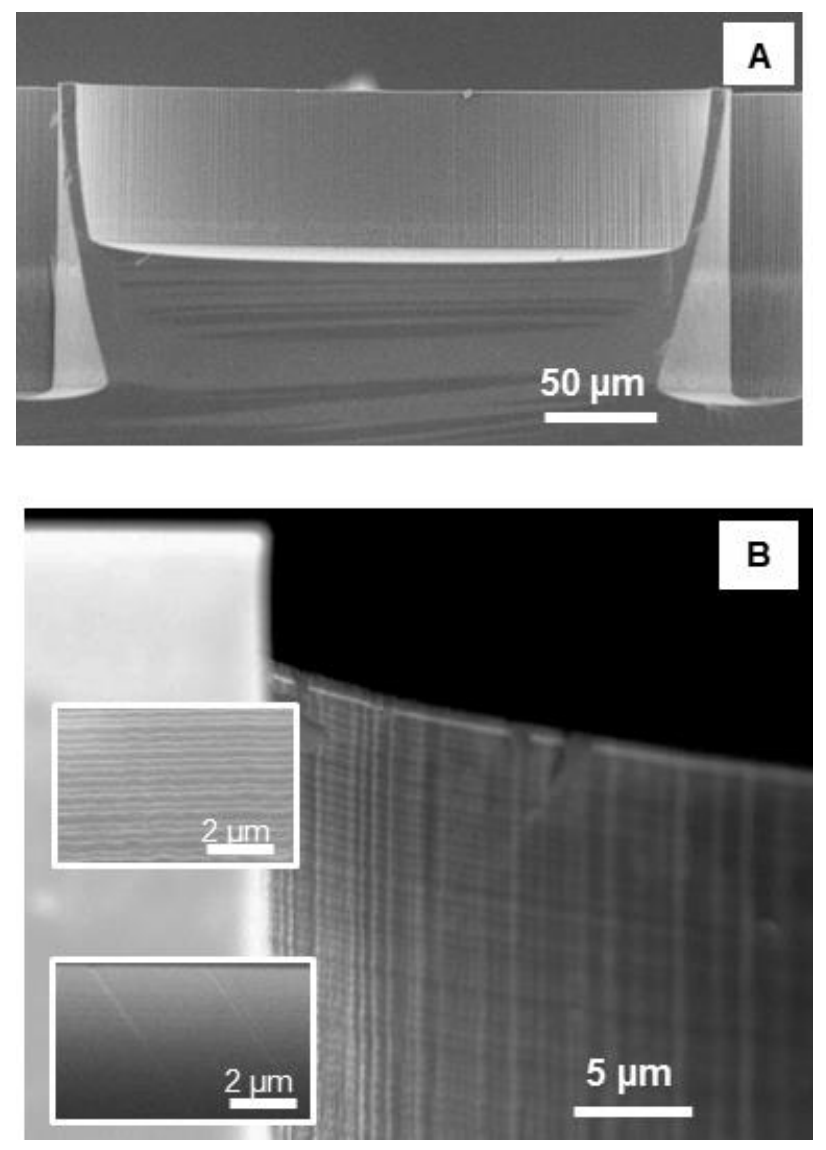

Fig.7. A. SEM image showing a positive sidewall profile for the Si master with $10 \mu \mathrm{m}$ wall thickness and $40 \mu \mathrm{m}$ separation distance, after 300 cycles of two-step DRIE etch, B. Roughness of the walls of Si master: Upper inset - without any surface treatment and lower inset with the oxide cleaning.

With the optimized DRIE process, without any additional surface treatment, we achieved scallops that are around $50 \mathrm{~nm}$ tall as shown in Fig.7.B (Upper inset). Apart from the scallops that appear due to the Bosch etching process, vertical striations due to line edge roughness of the etch mask are visible. This effect is enhanced after the plasma etching of the oxide layer and continues to increase further during DRIE $[25,26]$. It has been shown that, after the dry etching and mask oxide removal, the rough surfaces can be smoothened significantly by wet etches such as an isotropic Si etch [27]. Another interesting technique is to grow $500 \mathrm{~nm}$ oxide on top of the Si master and then etch this sacrificial oxide. In this way, the rough corners of $\mathrm{Si}$, those have been consumed when growing the oxide layer, can be removed. In Fig.7.B 
(Lower inset), it can be observed that after the sacrificial oxide growth and etching process, the sidewalls of the structure have become substantially smoother.

The final Si master is shown in Fig.8.A-B. The etched structures have smooth walls and a high aspect ratio. Fig.8.C shows the cross sectional profile obtained with a PLu Neox 3D Optical Profiler from Sensofar. The total depth of the separation trenches is measured to be $125 \mu \mathrm{m}$ with the reservoir depth being $85 \mu \mathrm{m}$. Thus for a $10 \mu \mathrm{m}$ thick wall, a high aspect ratio close to 8 is achieved.
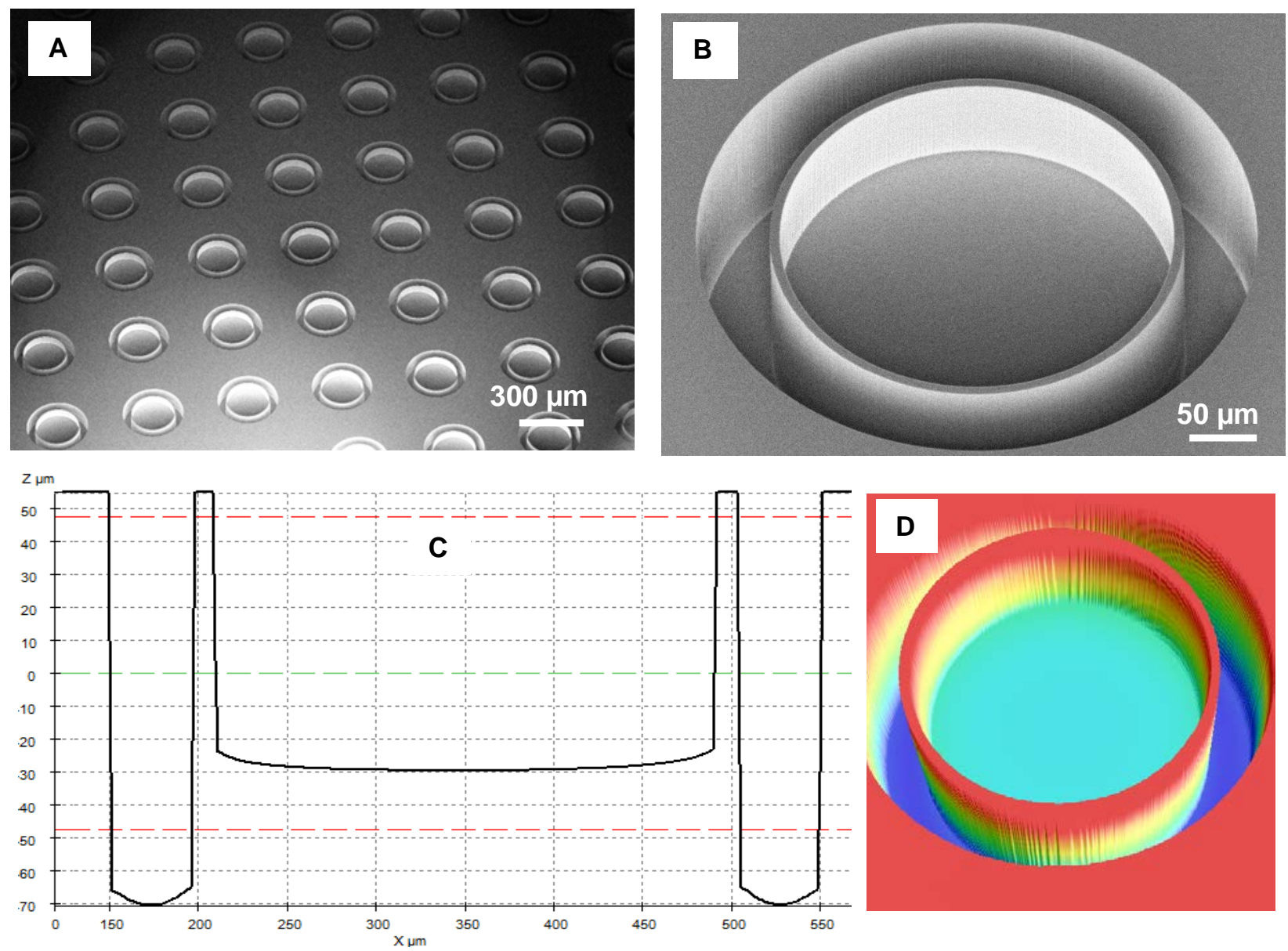

Fig.8. A. Final Si master with $10 \mu \mathrm{m}$ wide walls and $50 \mu \mathrm{m}$ wide separation trench, B. Close up view of one structure on the Si wafer, C. 3D optical profilometer analysis, D. Optical profilometer line-scan

\subsection{Ni stamp fabrication}

After fabrication of the Si master the $\mathrm{Ni}$ is electroplated. This is followed by the removal of the Si master in $\mathrm{KOH}$. Since the geometry of the microcontainers is cylindrical, the Si etch stops on the $\{111\}$ planes as shown in Fig.9.A. Since alkaline solutions all have a low etch rate in $\{111\}$ planes, Polysilicon etch solutions $\left(\mathrm{HF} / \mathrm{H}_{2} \mathrm{O}+\right.$ an oxidizing acid like $\mathrm{HNO}_{3}$ ) were considered to remove the remaining $\mathrm{Si}$ at a reasonable rate. However, these wet etch solutions also etch $\mathrm{Ni}$ 

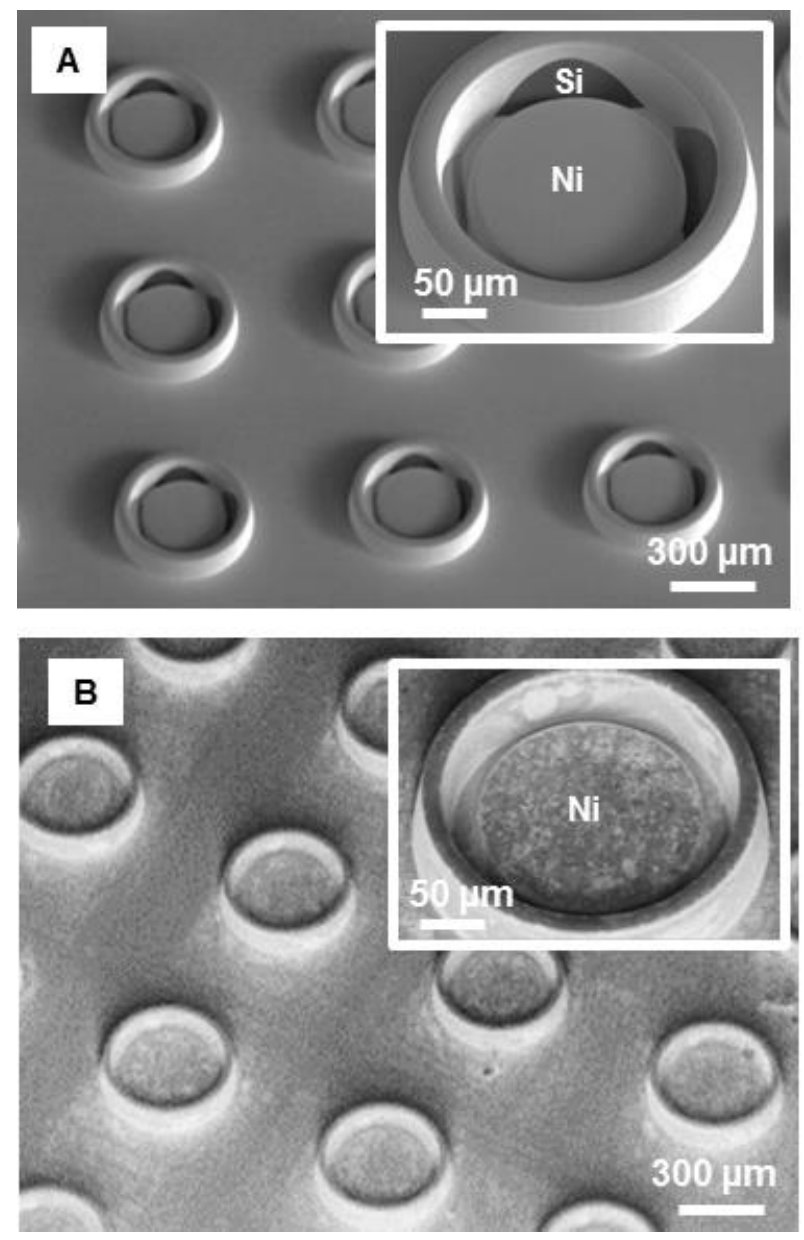

Fig.9. A. SEM image showing remaining unetched $\mathrm{Si}\{111\}$ planes after electroplating Ni and attempted release in $\mathrm{KOH}$, inset: $\mathrm{Close}$ up of one structure, B. Dry etching of $\mathrm{Si}\{111\}$ planes after electroplating and $\mathrm{KOH}$ release, inset: Close up of one structure.

[28]. Instead, dry etching of the remaining $\{111\}$ Si plane in $\mathrm{CF}_{4}$ plasma was tried but this process left a thin layer of residues on the stamp surface as shown in Fig.9.B. since fluorine reacts with $\mathrm{Ni}$.

Finally, an alternative approach was developed where a thin release layer was deposited on the Si master prior to the $\mathrm{Ni}$ electroplating. Since it was undesirable to increase the roughness of the Si surface, a $400 \mathrm{~nm}$ layer of LPCVD polysilicon is deposited at a very low temperature of $560^{\circ} \mathrm{C}$, where it becomes almost amorphous. The roughness of the amorphous Si layer on a standard Si wafer evaluated using ellipsometry was $2 \mathrm{~nm}$. Thus, deposition of the amorphous Si release layer adds negligibly to the overall roughness of the Si master sidewalls. After the release layer deposition, deposition of a $\mathrm{Cr} / \mathrm{Au}$ seed layer and then Ni electroplating proceeded as described above. During the $\mathrm{KOH}$ etch, the $\mathrm{KOH}$ attacks the amorphous $\mathrm{Si}$ and then the $\{111\}$ residues are eroded. As a result a Ni stamp with smooth walls and positive sidewall profile is achieved as shown in Fig.10.A-B. 

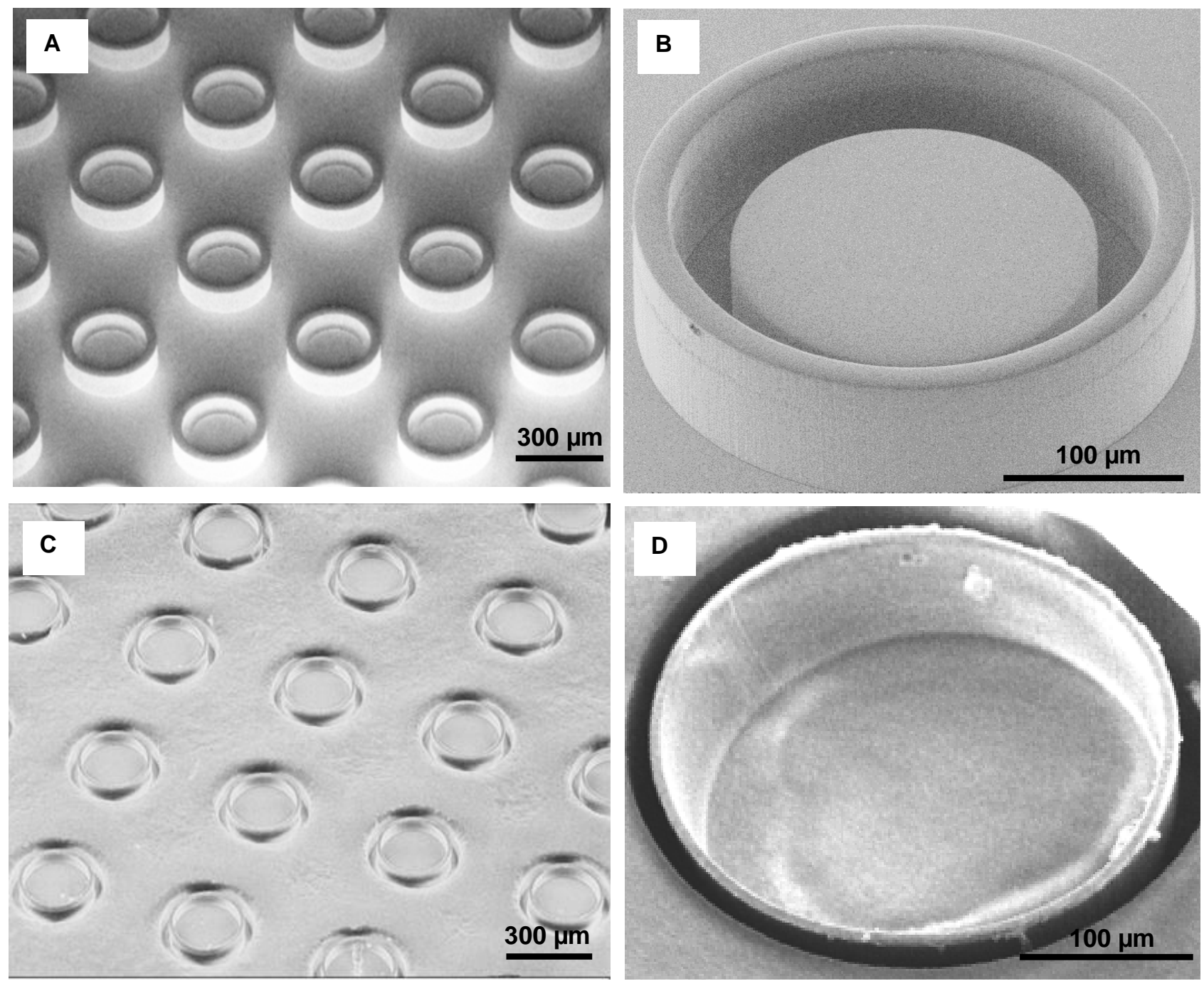

Fig.10. A. SEM micrograph of final Ni stamp, B. Close up of one structure on Ni stamp (220 $\mu \mathrm{m}$ inner disc and $30 \mu \mathrm{m}$ separation distance), C. Imprinted microcontainer in PLLA, D. Close up of one microcontainer (10 $\mu \mathrm{m}$ walls and $20 \mu \mathrm{m}$ separation distance)

\subsection{Hot embossing and structure replication}

As described in section 2.1 the diameter of the inner disc is varied from 220 , over 240,260 , to $280 \mu \mathrm{m}$ and the width of the outer ring structure is varied from 20 , over 30,40 , to $50 \mu \mathrm{m}$ on the Ni stamp. The effect of these variations on the etch depth on the Si master and subsequent Ni stamp and PLLA microcontainer replication has been analyzed using an optical profilometer. There are two dimensions we are mainly interested in: The reservoir depth in Si master $\left(D_{\text {Si1 }}\right)$ and PLLA (D PLLA1) or the corresponding inner circle height on the stamp $\left(\mathrm{H}_{\mathrm{Ni1}}\right)$, and the separation trench depth in Si master $\left(D_{\mathrm{si} 2}\right)$ and PLLA (D PLLA2) or the corresponding height of the outer ring on the stamp $\left(\mathrm{H}_{\mathrm{Ni2}}\right)$ as depicted in Fig.3. As shown in Fig.11, it can be observed that there are minor variations of the total etch depth of reservoir and separation trench in the Si master. The design variations of the patterns in the mask lead to the variations in etch depth of the Si master due to ARDE [29]. Since the aspect ratio for the separation trench is more that the aspect ratio for the reservoir, the differences in the depth are higher for the former. When the replication of Ni stamp from Si master and the PLLA microcontainer from the Ni stamp is considered (Fig.10.C), it can be seen that there is good replication fidelity (Fig.11). 
We have successfully replicated all the microstructures with varying dimensions on the Ni stamp into the PLLA film. This includes fabrication of microcontainers with $10 \mu \mathrm{m}$ wall thickness with an aspect ratio of 8 (Fig.10.D).

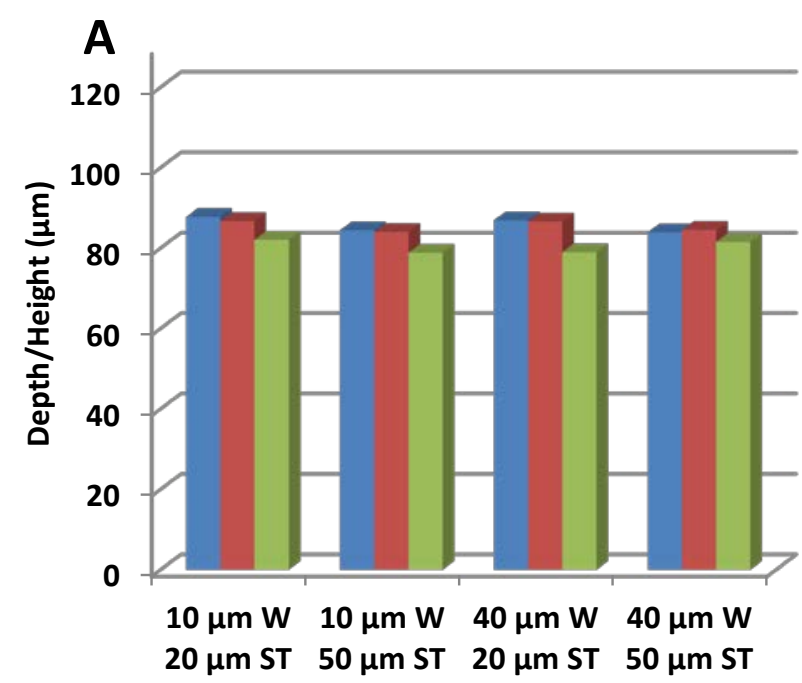

\begin{tabular}{ll|l|l}
$D_{\text {Si1 }}$ & $H_{\text {Ni1 }}$ & $D_{\text {PLA1 }}$
\end{tabular}
B

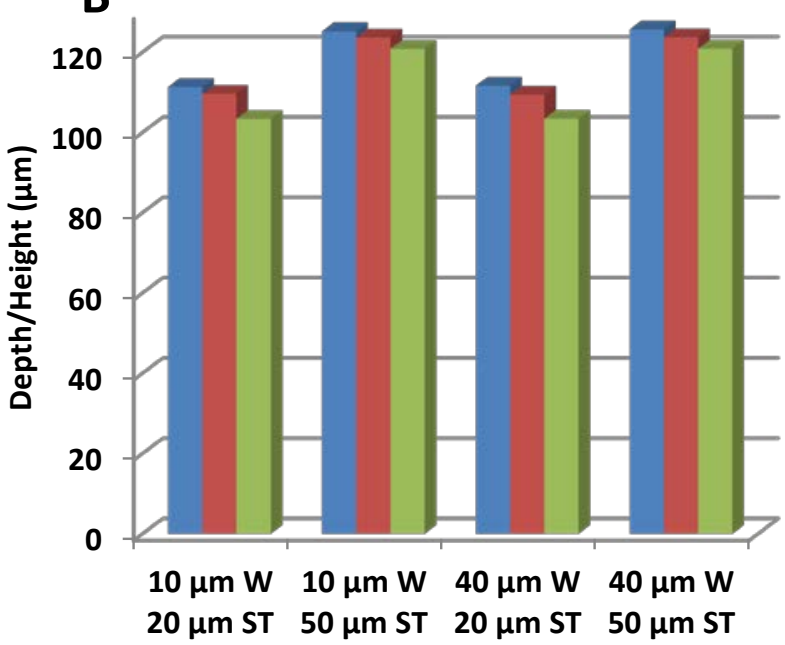

$\begin{array}{llll}\mathrm{D}_{\mathrm{Si} 2} & \mathrm{H}_{\mathrm{Ni2}} & \mathrm{D}_{\mathrm{PLLA2}}\end{array}$

Fig.11. Measurements and comparison of the critical dimensions on Ni stamp and in Si master and PLLA using optical profiler (W=wall, $\mathrm{ST}=$ separation trench): $\mathrm{A}$. The reservoir depth in Si master $\left(\mathrm{D}_{\mathrm{Si} 1}\right)$ and PLLA (D $\left.\mathrm{D}_{\mathrm{PLA1}}\right)$ or the corresponding inner circle height on the stamp $\left(\mathrm{H}_{\mathrm{Ni1}}\right)$, B. the separation trench depth in Si master $\left(\mathrm{D}_{\mathrm{Si} 2}\right)$ and PLLA ( $\left.\mathrm{D}_{\mathrm{PLLA} 2}\right)$ or the corresponding height of the outer ring on the stamp $\left(\mathrm{H}_{\mathrm{Ni} 2}\right)$. The standard error is $<1 \mu \mathrm{m}$ for all the samples and is not shown in the graph.

\section{CONCLUSION AND OUTLOOK}

We have successfully fabricated a Ni stamp with two leveled cylindrical microstructures for hot embossing in polymers. For this purpose, we have optimized the fabrication process flow and in particular the deep reactive ion etch process. The standard Bosch process is optimized by ramping the etch time and modifying the oxygen flow. Finally, microstructures with the desired features: smooth walls, positive taper, minimum undercut and no lateral etch are fabricated in Si to obtain a master. On this master, $\mathrm{Ni}$ is electroplated and a Ni stamp is achieved. This stamp is then molded into PLLA polymer films and good high fidelity replication of the Ni stamp is observed for trenches with a width of $20 \mu \mathrm{m}$ and a depth of $120 \mu \mathrm{m}$, and for walls with a width of $10 \mu \mathrm{m}$ and a height of $85 \mu \mathrm{m}$. Hence, microcontainers are successfully fabricated in a biopolymer layer. In future, the Ni stamp can be fabricated as thin shims for roll-to-roll printing in order to mass produce oral drug delivery microcontainers. The process can be easily used for various kinds of shapes, sizes and dimensions with minor changes in the process flow.

\section{ACKNOWLEDGEMENTS}

We would like to acknowledge financial support by NAMEC Villum Kann Rasmussen Centre of Excellence (65286) and by the Danish National Research Foundation's Center for Individual Nanoparticle Functionality (DNRF54). We would also like to thank Danchip staff for their support in developing the process flow, especially Chantal Silvestre for her guidance with the optical profiler and Frederik Stöhr for his help with the DRIE process.

\section{REFERENCES}


[1] Zhang, Ying, Hon Fai Chan, and Kam W. Leong. "Advanced materials and processing for drug delivery: the past and the future." Advanced drug delivery reviews 65, no. 1 (2013): 104-120.

[2] Worgull, Matthias. Hot embossing: theory and technology of microreplication. William Andrew, 2009.

[3] Chirra, Hariharasudhan D., Ling Shao, Natalie Ciaccio, Cade B. Fox, Jennifer M. Wade, Averil Ma, and Tejal A. Desai. "Planar Microdevices for Enhanced In Vivo Retention and Oral Bioavailability of Poorly Permeable Drugs." Advanced healthcare materials (2014).

[4] Nielsen, Line Hagner, Stephan Sylvest Keller, Keith C. Gordon, Anja Boisen, Thomas Rades, and Anette Müllertz. "Spatial confinement can lead to increased stability of amorphous indomethacin." European Journal of Pharmaceutics and Biopharmaceutics 81 , no. 2 (2012): 418-425.

[5] Nagstrup, Johan, Stephan Keller, Kristoffer Almdal, and Anja Boisen. "3D microstructuring of biodegradable polymers." Microelectronic Engineering 88, no. 8 (2011): 2342-2344.

[6] Chen, Zhifeng, Yunhua Gao, Rongguo Su, Chengwu Li, and Jinming Lin. "Fabrication and characterization of poly (methyl methacrylate) microchannels by in situ polymerization with a novel metal template." Electrophoresis 24, no. 18 (2003): $3246-3252$.

[7] Červenka, Petr, Walter Schrott, Zdeněk Slouka, Michal Přibyl, and Dalimil Šnita. "Hybrid gold-copper stamp for rapid fabrication of microchips."Microelectronic Engineering 98 (2012): 548-551.

[8] Ansari, Kambiz, Jeroen Anton van Kan, Andrew Anthony Bettiol, and Frank Watt. "Stamps for nanoimprint lithography fabricated by proton beam writing and nickel electroplating." Journal of Micromechanics and Microengineering 16, no. 10 (2006): 1967.

[9] Becker, EoWo, Wo Ehrfeld, Po Hagmann, A. Maner, and D. Münchmeyer. "Fabrication of microstructures with high aspect ratios and great structural heights by synchrotron radiation lithography, galvanoforming, and plastic moulding (LIGA process)." Microelectronic engineering 4, no. 1 (1986): 35-56.

[10] Chang, C. Y., Sen Yeu Yang, and J. L. Sheh. "A roller embossing process for rapid fabrication of microlens arrays on glass substrates." Microsystem technologies 12, no. 8 (2006): 754-759.

[11] Elders, J., H. V. Jansen, M. Elwenspoek, and W. Ehrfeld. "DEEMO: a new technology for the fabrication of microstructures." (1995): 238-243.

[12] Dentinger, Paul M., W. Miles Clift, and Steven H. Goods. "Removal of SU-8 photoresist for thick film applications." Microelectronic Engineering 61 (2002): 993-1000.

[13] Guo, Yuhua, Gang Liu, Ying Xiong, Jun Wang, Xinlong Huang, and Yangchao Tian. "Study of Hot Embossing Using Nickel and NiPTFE LIGA Mold Inserts."Microelectromechanical Systems, Journal of 16, no. 3 (2007): 589-597.

[14] Tanzi, Simone, Peter Friis Østergaard, Marco Matteucci, Thomas Lehrmann Christiansen, Jiri Cech, Rodolphe Marie, and Rafael Taboryski. "Fabrication of combined-scale nano-and microfluidic polymer systems using a multilevel dry etching, electroplating and molding process." Journal of Micromechanics and Microengineering 22, no. 11 (2012): 115008.

[15] Park, In-Soo, Jin-Soo Kim, Seong-Hun Na, Seung-Kyu Lim, Young-Soo Oh, and Su-Jeong Suh. "Fabrication of a two-step Ni stamp for blind via hole application on PWB." Microelectronic Engineering 87, no. 9 (2010): 1707-1710.

[16] Delaney, K. D., G. Bissacco, and D. Kennedy. "A Structured Review and Classification of Demolding Issues and Proven Solutions." International Polymer Processing 27, no. 1 (2012): 77-90.

[17] Marizza, Paolo, Stephan S. Keller, Anette Müllertz, and Anja Boisen. "Polymer-filled microcontainers for oral delivery loaded using supercritical impregnation."Journal of Controlled Release 173 (2014): 1-9. 
[18] Juan, Wen-Han, and S. W. Pang. "Controlling sidewall smoothness for micromachined Si mirrors and lenses." Journal of Vacuum Science \& Technology B 14, no. 6 (1996): 4080-4084.

[19] Srinivasan, Uthara, Michael R. Houston, Roger T. Howe, and Roya Maboudian. "Alkyltrichlorosilane-based self-assembled monolayer films for stiction reduction in silicon micromachines." Microelectromechanical Systems, Journal of 7, no. 2 (1998): $252-260$.

[20] Petersen, Ritika Singh, Rasoul Mahshid, Nis Korsgaard Andersen, Stephan Sylvest Keller, Hans Nørgaard Hansen, and Anja Boisen. "Hot embossing and mechanical punching of biodegradable microcontainers for oral drug delivery."Microelectronic Engineering (2014).

[21] Kawata, Hiroaki, Kensuke Kubo, Yuuta Watanabe, Junji Sakamoto, Masaaki Yasuda, and Yoshihiko Hirai. "Effects of mold side wall profile on demolding characteristics." Japanese Journal of Applied Physics 49, no. 6S (2010): 06GL15.

[22] Chen, Kuo-Shen, Arturo A. Ayón, Xin Zhang, and S. Mark Spearing. "Effect of process parameters on the surface morphology and mechanical performance of silicon structures after deep reactive ion etching (DRIE)."Microelectromechanical Systems, Journal of 11 , no. 3 (2002): 264-275.

[23] Wang, Lele, Dong Liang, Yu-Shuen Wang, and James P. McVittie. "STSetch2 Profile Characterization-Undercut Investigation for Silicon Trench Etching in STSetch2."

[24] Wu, Banqiu, Ajay Kumar, and Sharma Pamarthy. "High aspect ratio silicon etch: a review." Journal of Applied Physics 108, no. 5 (2010): 051101.

[25] Shin, J., G. Han, Y. Ma, K. Moloni, and Franco Cerrina. "Resist line edge roughness and aerial image contrast." Journal of Vacuum Science \& Technology B 19, no. 6 (2001): 2890-2895.

[26] http://spie.org/x93019.xml

[27] Lee, Kevin K., Desmond R. Lim, Lionel C. Kimerling, Jangho Shin, and Franco Cerrina. "Fabrication of ultralow-loss Si/SiO2 waveguides by roughness reduction." Optics letters 26, no. 23 (2001): 1888-1890.

[28] Williams, Kirt R., Kishan Gupta, and Matthew Wasilik. "Etch rates for micromachining processing-Part II." Microelectromechanical Systems, Journal of 12, no. 6 (2003): 761-778.

[29] Yeom, Junghoon, Yan Wu, and Mark A. Shannon. "Critical aspect ratio dependence in deep reactive ion etching of silicon." In TRANSDUCERS, Solid-State Sensors, Actuators and Microsystems, 12th International Conference on, 2003, vol. 2, pp. 1631-1634. IEEE, 2003. 